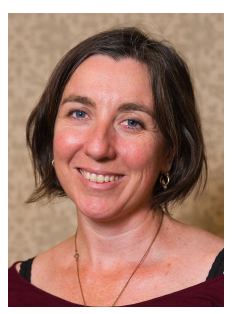

Tanya M Howard

Centre for Agriculture and Law

School of Law

University of New England

Australia

\section{SOIL GOVERNANCE: ACCESSING CROSS-DISCIPLINARY PERSPECTIVES}

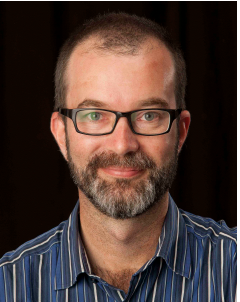

Soil provides the foundation for agricultural and environmental systems, and are subject to a complex governance regime of property rights and secondary impacts from industry and domestic land use. Complex natural resource management issues require approaches to governance that acknowledge uncertainty and complexity. Theories of next generation environmental governance assume that inclusion of diverse perspectives will improve reform directions and encourage behaviour change. This paper reports on a qualitative survey of an international workshop that brought together cross-disciplinary perspectives to address the challenges of soil governance. Results reveal the challenges of communicating effectively across disciplines. The findings suggest that strategies for improved soils governance must focus on increasing communications with community stakeholders and engaging land managers in designing shared governance regimes. The need for more conscious articulation of the challenges of cross-disciplinary environments is discussed and strategies for increasing research collaboration in soils governance are suggested. The identified need for more systematic approaches to cross-disciplinary learning, including reporting back of cross-disciplinary initiatives to help practitioners learn from past experience, forms part of the rationale for this paper.

\title{
Introduction
}

Natural resources, such as water, soil, mineral and botanical resources, are assets that are derived from the natural environment. These naturally occurring resources provide the capacity for agriculture and aquaculture, and are the foundations of economic trade and development. When people interact with natural resources to control, change, improve or disturb an ecosystem's balance, they are undertaking a form of management. Natural resource management (NRM) focuses attention on the interactions and impacts of human populations on the environment across a range of temporal and spatial scales. ${ }^{1}$ Natural resource management can be complex and resistant to simple policy fixes. Issues, such as environmental degradation and resource-scarcity, cross land tenures, implicate livelihoods and challenge short-term thinking and familiar decision-making processes. ${ }^{2}$ Natural resource governance describes the mechanisms developed through policy, legislation and everyday interactions to influence or enact decisions about how these natural resources will be managed. ${ }^{3}$

As population growth, consumption demands and climate change increase pressures on shared resources, there is an need for improved governance structures that balance vested interests with considerations of social and environmental impacts, and enable communities to be involved in making decisions about the management of natural resources. ${ }^{4}$ If 'public participation is widely considered a fundamental aspect of good governance'

\footnotetext{
This article is based on research undertaken with the support of the Australian Research Council (Project No LP110100659) 'Next Generation Rural Resource Governance' and project partners: Australian Cotton Research and Development Corporation; Pennsylvania State University; Soil Conservation Service of Iceland; Australian Government Department of Sustainability, Environment, Water, Population and Communities; Tamar NRM, RDA Tasmania; the Tamar and Namoi region communities.

1 Steve Dovers, 'Embedded Scales: Interdisciplinary and Institutional Issues' in Valerie Brown, John Harris and Jacqueline Russel (eds), Tackling Wicked Problems Through the Transdisciplinary Imagination (Earthscan, 2010).

2 Catherine Allan, 'Can Adaptive Management Help us Embrace the Murray-Darling Basin's Wicked Problems?' in Claudia PahlWostl, Pavel Kabat and Jörn Möltgen (eds), Adaptive and Integrated Water Management (Springer, 2008$) 61$.

3 G Borrini-Feyerabend et al, A Primer on Governance for Protected and Conserved Areas (IUCN, 2014); S Ryan et al, 'Australia's NRM Governance System: Foundations and Principles for Meeting Future Challenges' (2010) <http://www.actnrmcouncil.org.au/node/193>.

${ }^{4}$ Kevin Taft, 'Fossil Fuels, Global Warming and Democracy: A Report from a Scene of the Collision' (University of Western Sydney, 2014) <http://apo.org.au/node/41234>.
} 
then it is necessary to explore how existing governance structures can engage land managers and community stakeholders to make natural resource decisions together. ${ }^{6}$

The fundamental importance of soil to the wellbeing of all terrestrial life forms is well canvassed in the literature $^{7}$ and environmental histories describe sophisticated societies crumbling because of soil degradation. ${ }^{8}$ Soils are fragile and quickly damaged. They take decades and centuries to repair and reform. Soils face increasing pressures from human development, including from erosion, contamination and sealing. ${ }^{9}$ It is troubling, then, that soil health around the world has been slow to climb onto the governance agenda, indicating that they are 'a poor cousin among NRM issues ... [that] rarely excite the public imagination and do not lend themselves to media campaigns for the mass market'. ${ }^{10}$

Research suggests that part of the problem lies in the narrow way soil has been cast as a technical, natural sciences phenomenon, with little regard for social drivers or the political and economic dynamics of increasingly competitive land uses. ${ }^{11}$ This is not to downplay the important role of a technical focus. Interactions between geology, mineralogy, soil biota, carbon and other elemental cycles are complex and far from entirely understood. Soils are fundamental to the natural sciences and soils science is a venerable academic specialty. However, as with other natural resource issues, the way humans manage their impacts on soils requires equal consideration of physical and social elements to successfully address these impacts. Historically, soil science has been heavily skewed towards chemistry and physics, limiting the development of soil ecology and biodiversity messages that connect soil health to environmental conservation. ${ }^{12}$ For governments, industry and land managers, bulldozers and engineering works have often been the dominant modes of soil conservation, rather than an integrated approach that considers multiple landscape values and the interactions between management actions. ${ }^{13}$ To develop more effective soil management there is a need to move beyond an exclusive focus on the biophysical, to consider how legal frameworks, management practices and human activities combine in soil governance regimes. ${ }^{14}$

A recent attempt to address the diverse drivers of soil health is the Global Soils Partnership (GSP), which was formed in 2013 by the United Nations' Food and Agriculture Organization and is the culmination of three decades of initiatives in international soil governance. ${ }^{15}$ Its main specialist advisory body is the Intergovernmental Technical Panel on Soils, ${ }^{16}$ whose membership is drawn from traditional soil science disciplines. ${ }^{17}$ The technical panel omits economists, legal scholars and social scientists, although the 'five

5 Marianne Dellinger, 'Ten Years of the Aarhus Convention: How Procedural Democracy Is Paving the Way for Substantive Change in National and International Environmental Law' (2012) 23(2) Colorado Journal of International Environmental Law \& Policy 309.

6 Cameron Holley, 'Public Participation, Environmental Law and New Governance: Lessons for Designing Inclusive and Representative Participatory Processes' (2010) 27(5) Environmental and Planning Law Journal 32; Jade Herriman, 'Local Government and Community Engagement in Australia' (Working Paper No 5, Australian Centre of Excellence for Local Government, University of Technology, 2011); Mark Evans and Richard Reid, 'Public Participation in an Era of Governance: lessons from Europe for Australian Local Government' (Australian Centre of Excellence for Local Government, 2014) $<$ http: //apo.org.au/node/38341>.

7 Marcel G A van der Heijden, Richard D Bardgett and Nico M van Straalen, 'The Unseen Majority: Soil Microbes as Drivers of Plant Diversity and Productivity in Terrestrial Ecosystems' (2008) 11 Ecology Letters 296.

8 Clive Ponting, A Green History of the World: The Environment and the Collapse of Great Civilizations (Penguin, 1991); Daniel Hillel, Out of the Earth: Civilization and the Life of the Soil (Free Press, 1991); R David, Montgomery, Dirt: The Erosion of Civilizations (University of California Press, 2007); Jared Diamond, Collapse: How Societies Choose to Fail or Succeed (Viking Penguin, 2005).

9 Jes Weigelt et al, 'Towards Integrated Governance of Land and Soil: Addressing Challenges and Moving Ahead' (Issue Paper', Global Economic Symposium, 2012) <http://www.global-economic-symposium.org/knowledgebase/losing-ground/virtuallibrary/towards-integrated-governance-of-land-and-soil-addressing-challenges-and-moving-ahead.201d/at_download/file> .

${ }^{10}$ A Campbell, 'Managing Australia's Soils: A Policy Discussion Paper' (Prepared for the National Committee on Soil and Terrain (NCST) through the Natural Resource Management Ministerial Council (NRMMC), 2008),

<http://www.clw.csiro.au/aclep/documents/Soil-Discussion-Paper.pdf>

${ }^{11}$ Weigelt et al, above $\mathrm{n} 9$.

${ }^{12}$ Campbell, above $\mathrm{n} 10$.

13 Ibid.

${ }^{14}$ Andrea Koch et al, 'Soil Security: Solving the Global Soil Crisis' (2013) 4(4) Global Policy 434; see also, K Killham, 'Foresight Project on Global Food and Farming Futures - Integrated Soil Management - Moving Towards Globally Sustainable Agriculture' (2011) 149 Journal of Agricultural Science (2011) 29; and Weigelt et al, above n 9.

15 These include the World Soil Charter, the soils work of the IUCN, and the World Soils Agenda of the International Union of Soils Sciences: Campbell, above n 10.

${ }^{16}$ FAO, Intergovernmental Technical Panel on Soils ('ITPS')(2015) Global Soils Partnership <http://www.fao.org/globalsoilpartnership/intergovernmental-technical-panel-on-soils/en/>. 17 lbid 
pillars' on which the GSP rests include management, policy, education and social development. ${ }^{18}$ Attempts to address complex natural resource governance must do better at integrating diverse disciplinary and professional perspectives, recognising that

Because of their complexity, many [wicked]... problems are not conducive to centralized hierarchical decision-making. Rather, they often require the knowledge, commitment, and action of multiple levels of government, special interests, and the general public over long periods of time. ${ }^{19}$

This need for multiple perspectives suggests an important role for cross-disciplinary research that aims to combine different bodies of knowledge to address complex natural resource governance issues. ${ }^{20}$ Crossdisciplinary research challenges conventional research strategies by inviting uncertainty into the research process. Researchers explore productive synergies between varying academic methods and perspectives, ${ }^{21}$ which requires a willingness to explore significant epistemological differences while looking for potential overlaps in both subject matter and methodological approaches. The identified need for more systematic approaches to cross-disciplinary learning, including reporting back of cross-disciplinary initiatives to help practitioners learn from past experience, forms part of the rationale for this paper. ${ }^{22}$

When participants generate a cross-disciplinary research agenda, they must confront the differences between academic disciplines. Although discomfort is likely, there are practical strategies to assist participants to deal with their discomfort while retaining the benefits of all disciplines involved. These strategies are commonly utilised in community development where issues of power and knowledge are acknowledged as key considerations in achieving successful outcomes ${ }^{23}$ Cross-disciplinary ventures must address struggles for epistemological dominance and integrate different belief systems, in a similar fashion to community development or participatory research strategies. ${ }^{24}$

This paper presents the results of a qualitative survey from an international cross-disciplinary workshop to reveal insights into both soil governance and cross-disciplinary research practice. The methodologies of the workshop and the qualitative survey are described. This is followed by analysis of the survey results and a discussion of their relevance to soil governance. The paper concludes with recommendations for crossdisciplinary research directions aimed at increasing community and stakeholder participation in natural resource governance.

\section{The Iceland workshop: Methodology}

Bringing together scholars and practitioners from Europe, North America, Australia, Africa and North East Asia, the Iceland workshop considered soil governance as a foundation of agricultural and environmental health. ${ }^{25}$ The four-day workshop combined presentations and collaborative, cross-disciplinary activities, which aimed to develop innovative research directions for improving soil governance. Specific themes were explored in depth, including community engagement; partnered governance and co-regulation; behavioural effectiveness; and implementation. Participants were allocated to a theme with consideration of their research interests,

\footnotetext{
${ }^{18}$ FAO, The 5 Pillars of Action (2015) Global Soil Partnership <http://www.fao.org/globalsoilpartnership/the-5-pillars-ofaction/en/>.

${ }^{19}$ Thomas C Beierle, 'Using Social Goals to Evaluate Public Participation in Environmental Decisions' (1999) 16(3-4) Review of Policy Research 75, 77.

${ }^{20}$ In this paper, 'cross-disciplinary' is used in a broad sense and interchangeable with similar terms, such as multidisciplinary and inter-disciplinary. Some scholars make clear distinctions between these terms (see Bammer, below $\mathrm{n} 21$ and Strang, below $n$ 30).

${ }^{21}$ G Bammer, 'Strengthening Interdisciplinary Research: What it is, What it Does, How it Does it and How it is Supported' (Report for the Australian Council of Learned Academies, Melbourne, 2012); Terry Hillman et al, 'Multidisciplinary Approaches to Natural Resource Management' (2005) 552(1) Hydrobiologia 99; M Brugnach et al, 'More is not Always Better: Coping with Ambiguity in Natural Resources Management' (2011) 92(1) Journal of Environmental Management 78.

22 Bammer, above n 21; James Fitzsimons and Geoff Wescott, 'The Importance of Interdisciplinary Research in Conservation Networks: Lessons from South-Eastern Australia' in lan Pulsford, James Fitzsimons and Geoff Wescott (eds), Linking Australia's Landscapes: Lessons and Opportunities from Large-Scale Conservation Networks (CSIRO publishing, 2013).

${ }^{23}$ Workshop IDS, 'Participation, Policy Change and Empowerment' in J Holland and J Blackburn (eds), Whose Voice? Participatory Research and Policy Change (Intermediate Technology Publications, 1998) 192; Robyn Eversole, 'Community Agency and Community Engagement: Re-Theorising Participation in Governance' (2011) 31(1) Journal of Public Policy 51; Frank Fischer, Citizens, Experts and the Environment: The Politics of Local Knowledge (Duke University Press, $1^{\text {st }}$ ed, 2005).

${ }^{24}$ Andreas Neef and Dieter Neubert, 'Stakeholder Participation in Agricultural Research Projects: A Conceptual Framework for Reflection and Decision-Making' (2011) 28(2) Agriculture and Human Values 179.

${ }^{25}$ Roger Croft, Healing the Land: The Story of Land Reclamation and Soil Conservation in Iceland (Soil Conservation Service of Iceland, 2011); Andres Arnalds, 'Farmers Heal the Land: A Social License for Agriculture in Iceland' in Jacqueline Williams and Paul Martin (eds), Defending the Social License of Farming: Issues, Challenges and New Directions for Agriculture (CSIRO publishing, 2011) 83.
} 
specialised knowledge and attention to encouraging a mix of disciplinary backgrounds. Theme leaders were delegated from the organising team and these leaders invited participants to share resources through an online forum and encouraged debate and exchange of ideas through emails over several months before the workshop. A requirement for each theme was to develop a presentation for the workshop sessions that would introduce and explore the theme in more detail, with particular attention to soil governance.

The authors of this paper administered a written questionnaire to workshop participants, who responded anonymously. The questionnaire utilised a mix of closed- and open-ended questions, and was analysed for emerging and recurring themes to reveal cross-disciplinary research directions for soil governance. ${ }^{26}$ Basic demographic information was also collected. To provide feedback to the workshop organisers, the survey included some questions about the workshop format itself. The questionnaire explored three key areas of interest to the authors: community engagement ${ }^{27}$, co-regulation, ${ }^{28}$ and cross-disciplinary scholarship.

\section{Results}

Respondents were evenly spread across age groups, with a majority representation from the US, Australia and Iceland - reflecting the key partners in the research project ${ }^{29}$ - with other attendees from Africa, Europe, the UK and Asia. Over half of the respondents situated themselves in the natural sciences, with the remainder spread across law, social science and economics (see Figure 1). Respondents recorded a strong preference for cross-disciplinary learning environments, indicating a high level of comfort with the workshop format, the usefulness and applicability of cross-disciplinary learning to their own work, and the opportunity to gain new insights from this kind of interaction. Responses reflected an awareness of self-reflective learning and a desire to learn new perspectives.

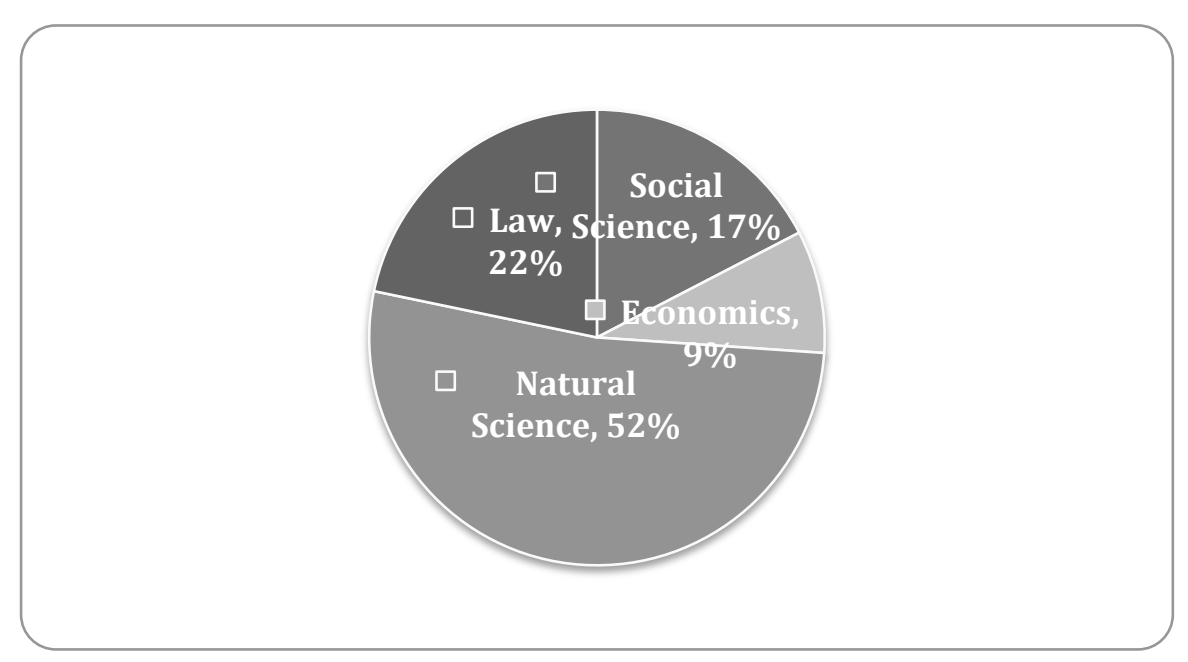

Figure 1: Academic and professional disciplines at the Iceland Workshop $(n=30)$

Respondents suggested that cross-disciplinary activity is valuable in itself as a research practice that can find 'creativity and innovation at the intersection of difference' and by 'getting out of our ivory towers and fixed mindsets'. The academic benefits of cross-disciplinary interaction were described as '[informing] my own theory' and encouraging 'institutional innovation'. Respondents saw the workshop as offering concrete

\footnotetext{
${ }^{26}$ Helene Joffe, 'Thematic Analysis' in D Harper and A R Thompson (eds), Qualitative Research Methods in Mental Health and Psychotherapy: A Guide for Students and Practitioners (John Wiley and Sons, $1^{\text {st }}$ ed, 2012); H R Bernard and G W Ryan, Analysing Qualitative Data: Systematic Approaches (Sage, 2010); W L Neuman, Social Research Methods (Allyn and Bacon, $7^{\text {th }}$ ed, 2011).

${ }^{27}$ The term community engagement is used as synonymous with public participation. This reflects an interaction between the Australian vernacular of public policy, and the international terminology of ecologically sustainable development principles. Both phrases carry an assumption that non-expert members of an affected population have a right to contribute to the design of solutions or strategies to address complex natural resource management issues.

28 'Co-regulation' means governance regimes in which government and non-government parties share regulatory tasks. It is a mid-point between direct government regulation ('command-and-control') and voluntary self-regulation.

${ }^{29}$ The project is a major, multi-collaborator research program focused on proposing the next generation of integrated natural resource management laws and institutions. The impetus is that, notwithstanding significant investments and legal interventions, rural landscapes continue to degrade. The intention of the research is to propose innovations that overcome identified limitations to present governance arrangements. See the Australian Centre for Agriculture and Law for more information: <http://www.une.edu.au/research/research-centres-institutes/the-australian-centre-for-agriculture-andlaw/research>.
} 
opportunities to 'strengthen connections between participants and ... contribute to further collaboration', with 'networks established, new ideas generated to deal with current research problems [and] ... broadening my perspective'.

However, respondents also commented on the difficulty of building rapport in a structured workshop environment: 'I felt ... I was just beginning to effectively engage the other members of the group by the end of the week' and made practical suggestions to improve the format such as 'fewer/shorter presentations, more conversation' and 'a little more time for interest-based small group conversation'. Respondents also highlighted the importance of acknowledging the philosophical challenges that may arise in a cross-disciplinary environment by 'warning participants that moments can be messy and they need to work on themselves to understand this' and establishing some ground rules such as 'more humility and attentiveness'.

Some commented on the need for more diverse interests to be represented, extending the cross-disciplinary into the cross-sectorial by inviting 'a broader landscape of individuals that may not be as steeped in the traditions of NRM' and bringing in 'stakeholder representatives who are making decision ... so we also take views from them'.

Although there were several months of electronic networking and preparation prior to the workshop, respondents offered suggestions for reducing the amount of time spent 'getting up to speed' by 'organis[ing] more systematically several discussion papers per group and make them available one month prior to the meetings'. Others supported attempts to establish 'greater clarity beforehand of the workshop' by implementing 'a stricter regime of pre-preparation to ensure that there is less start-up time'.

On average, all four disciplinary groups (social sciences, economics, natural sciences, and law) responded favourably to concepts of shared governance, or partnerships between regulators and land managers to develop new ways of regulating soil impacts. Strategies of co-regulation were seen to enhance management of the environment, increase transparency and accountability, lower compliance costs for citizens and governments, simplify legal compliance, and promote fairness.

Responses to open-ended questions about barriers to effective co-regulation and possible solutions were coded into barrier and solution categories (Table 1). A lack of commonality and misaligned interests amongst players in a potential co-regulatory regime was identified as a significant barrier, with better engagement of stakeholders seen as a 'solution' strategy.

Table 1: Barriers and solutions for effective co-regulation and contributions from each discipline

\begin{tabular}{|c|c|c|c|c|c|c|}
\hline & & & & scipl & & \\
\hline & & SS & $\mathrm{E}$ & NS & $\mathrm{L}$ & NR \\
\hline & Lack of commonality, misaligned interests & & & & & \\
\hline & Design and Implementation factors & & & & & \\
\hline & Corruption, lack of transparency \& accountability & & & & & \\
\hline ¿ & Lack of trust & & & & & \\
\hline$\frac{\mathrm{L}}{\sigma}$ & Power differences and inequities & & & & & \\
\hline & Lack of understanding of co-regulation as a policy option & & & & & \\
\hline & Social, cultural and economic factors & & & & & \\
\hline & Uncertainty about environmental effectiveness & & & & & \\
\hline & Better engagement of stakeholders & & & & & \\
\hline & Accountability mechanisms & & & & & \\
\hline & Education \& capacity building & & & & & \\
\hline & Research & & & & & \\
\hline & Transparency & & & & & \\
\hline$\tilde{\simeq}$ & Incentives & & & & & \\
\hline . & Marketing & & & & & \\
\hline ב & Institutional restructuring & & & & & \\
\hline œ & Resourcing & & & & & \\
\hline & Policy development & & & & & \\
\hline & Systems approach & & & & & \\
\hline & Ensure bona fides before proceeding & & & & & \\
\hline & Joint responsibility & & & & & \\
\hline & Adaptive management & & & & & \\
\hline & & SS & $\mathrm{E}$ & NS & $\mathrm{L}$ & NR \\
\hline
\end{tabular}

* $S S=$ social sciences, $E=e c o n o m i c s, N S=$ natural sciences, $L=l a w, N R=$ not recorded. Hatching shows where a group's responses contributed to the construction of a barrier/solution category.

The survey then explored concepts of stakeholder engagement in more detail. Respondents across all 
disciplines held expectations of direct outcomes, such as improved policy making and increased legitimacy for decision-making. Education of the 'community' was seen as the main reason for conducting community engagement, with a focus on building capacity to ensure more effective implementation of NRM strategies. Capacity to participate in less technocratic, 'bottom up' governance models was seen as lacking in community members, as well as decision-makers and scientists. This lack of capacity was seen to reduce innovation in the design and implementation of community governance alternatives, and was linked to inadequate resourcing of these alternatives. Respondents agreed on the need to work with stakeholders to develop a common purpose when addressing soil governance issues, however this identified lack of capacity was seen to foster confusion in objectives and to result in uneven power dynamics that undermined collective action.

Respondents tended to describe the benefits of community engagement in relation to their particular field of work, demonstrating the influence of personal experiences within a cross-disciplinary context. Almost all respondents had experience of participation in some kind of community engagement activity. Two main themes emerged that reflected a distinction between transformational and functional perspectives of community engagement (Table 2). The transformational responses were expressed as features of a process or activity: 'inclusiveness ... sharing of power and knowledge ... respectful ... reciprocal' were the attributes of effectiveness. The functional perspective described attributes such as: community acceptance of change and regulation; ownership of the issue; achieving natural resource governance outcomes; and a commitment to take action. A minority of respondents linked community engagement with broader governance goals of improving democratic practice and breaking down expert dominance in environmental decision-making.

Table 2: Analysis of respondent expectations for stakeholder engagement.

\begin{tabular}{ll}
\hline Transformational & Functional \\
\hline Principled & Rational \\
Intrinsic & Instrumental \\
Inherent good & Outcome focus \\
Democratic & Pragmatic \\
Empowering & Efficient \\
Human-right & Cost-effective \\
Social & Legal \\
Transformational & Functional \\
\hline
\end{tabular}

\section{Discussion}

The cross-disciplinary approach brought useful perspectives to the exploration of how different stakeholders could be involved in developing innovative, shared governance arrangements. Participants in the workshop were certainly capable of providing thoughtful and useful reflections on co-regulation, which, for most, was a subject matter outside their own discipline. Natural scientists explicitly identified social and cultural dimensions, and these were used to construct a distinct barrier category. The strong response from the natural scientists to corruption, accountability and transparency as a barrier suggests they look to lawyers to strengthen the constitutional, legal and regulatory regimes. All disciplinary groups identified the barrier 'power differences and inequities', and the solution 'better engagement of stakeholders', suggesting that respondents readily perceived the cross-disciplinary nature of soils governance.

The cross-disciplinary dialogue facilitated during the workshop revealed a persistent tension between an insistence on education and extension driven by technical expertise, and commitments to fostering democratic citizen knowledge. This tension was not satisfactorily resolved during the workshop, although productive discussions between these positions led to growing 'common ground' in acknowledging the epistemological differences that existed. Developing awareness of these pre-existing influences was a significant outcome of the cross-disciplinary process, and enabled participants to move away from a polarised debate to consider how decision-making processes, power imbalances and personal history could be taken into account in attempts to improve community engagement in soil governance.

These results echo the observations of other scholars of cross-disciplinary initiatives specifically formed around natural resource management issues. ${ }^{30}$ Scholarship in this area identifies significant tensions between academic disciplines which have evolved from different knowledge cultures. The development of distinct

\footnotetext{
${ }^{30}$ Hillman et al, above n 21; Veronica Strang, 'Integrating the Social and Natural Sciences in Environmental Research: A Discussion Paper' (2009) 11(1) Environment, Development and Sustainability 1; Heather Aslin and Kirsty Blackstock, 'Now I'm Not an Expert in Anything: Challenges in Undertaking Transdisciplinary Inquiries Across the Social and Biophysical Xciences' in Valerie A Brown, John A Harris, JacquelingY Russell (eds), Tackling Wicked Problems Through the Transdisciplinary imagination (Earthscan, 2010) 117.
} 
identities within academic disciplines can make it difficult to find intellectual common ground in crossdisciplinary endeavours. Rooted in ontological worldviews, beliefs about what constitutes knowledge create theoretical and empirical barriers to successful cross-disciplinary collaboration. ${ }^{31}$ These barriers include the different temporal and spatial scales that exert influence on research design; ${ }^{32}$ the real challenges of combining data and information from different disciplines; ${ }^{33}$ and the difficulty of delivering results that are meaningful across a range of disciplines. ${ }^{34}$

Traditional delineations of the different types of cross-disciplinary research can help clarify the objectives of an initiative by forcing designers to think about the process by which researchers are to interact: Are we designing a 'sequential process whereby researchers in different disciplines work independently, each from his or her own discipline-specific perspective?' Or an 'interactive process in which researchers work jointly, each drawing from his or her own discipline specific perspective?' Or an 'integrative process in which researchers work jointly to develop and use a shared conceptual framework that synthesizes and extends disciplinespecific theories, concepts, methods?' 35

The Iceland workshop attempted to develop an interactive process through pre-workshop communication by email, setting up cross-disciplinary groups that were expected to work on thematic presentations and develop effective working relationships in advance of the meeting. The challenges of working remotely, across time zones and without the advantage of pre-existing professional relationships led to a less integrated, more sequential approach to knowledge sharing. The short time frame limited the ability of the group to move beyond this sequential stage and, while the survey results indicate a pre-disposition to cross-disciplinary work, the design limitations made an integrative process difficult to achieve in practice.

\section{Conclusion}

The cross-disciplinary perspectives represented at the Iceland workshop provide valuable insights for improving soil governance. Of particular significance is the suggested potential for shared governance regimes to increase community participation. Stakeholder engagement emerged as a common ingredient for possible reform and innovation across all disciplines.

While there is much agreement about the challenges of 'wicked' problems, the complex issue of how best to design and improve natural resource governance regimes is often addressed from within specific disciplines. A lack of dialogue between the social and natural sciences sees technical solutions fail to address the human elements of soil management. A failure to consider the real-politik of environmental decision-making leads to a growing disconnection between soils science, and regulatory and policy responses, thus frustrating reform and leading to ongoing soil degradation. If complex natural resource issues are to be adequately addressed, they must integrate understanding of both social and environmental factors within the context of normative influences, such as human behaviour, political legitimacy and legal constructs of equity, fairness and enforcement.

Conducting cross-disciplinary research is a challenging undertaking. A lack of standardised terminology and different understandings of the concept make it difficult for researchers to learn from previous experiences. This paper makes a modest contribution to the challenge by sharing findings that may assist other academics, public policy analysts, community members and practitioners to work across boundaries. The Iceland

${ }^{31}$ Hillman et al, above n 22; Valerie Brown, 'Conducting an Imaginative Transdisciplinary Inquiry' in Valerie A Brown, John A Harris and Jacqueline Y Russell (eds), Tackling Wicked Problems Through the Transdisciplinary Imagination (Earthscan, 2010).

${ }^{32}$ Dovers, above $\mathrm{n} 1$.

${ }^{33}$ Elizabeth Fisher et al, 'Maturity and Methodology: Starting a Debate About Environmental Law Scholarship' (2009) 21(2) Journal of Environmental Law 213; Neef and Neubert, above $n 24$.

${ }^{34}$ H R Maier et al, 'Uncertainty in Environmental Decision Making: Issues, Challenges and Future Directions' in A A Voinov, A E Rizzoli, A Jakeman and S H Chen (eds), Developments in Integrated Environmental Assessment (Elsevier, vol 3, 2008) 69; Carolyn Hendriks, 'Inclusive Governance for Sustainability' in Valerie Brown, John Harris and Jacqueline Russel (eds), Tackling Wicked Problems Through the Transdisciplinary Imagination (Earthscan, 2010).

${ }^{35}$ Stokols (2008) quoted in Bammer, above n 21, 79. Bammer's six-part framework provides a useful departure for the design of prospective cross-disciplinary initiatives. The first question is: 'For what and for whom?', which focuses on the aims that the interdisciplinary research is trying to achieve. Second question: 'Of what?', in order to identify the disciplines and practitioner knowledge sought to be combined, the end-user perspectives sought to be addressed, as well as the epistemologies, languages, and cultures to be included. Third question: 'What context?', ie the context in which the research is occurring, ranging from drivers for action to the scale at which the interdisciplinary research is planned. Fourth question: 'By whom?', which centres on the decision-making process for the interdisciplinary initiative. Fifth question: 'How?', in terms of the theoretical underpinning, methods, transparency and accountability of the research. And finally: 'What impact?', which identifies whether the initiative achieved its aims and other positive and negative outcomes. 
experience suggests that attention to the design, implementation and evaluation stages of cross-disciplinary research activities is an important direction for future research. Established cross-disciplinary frameworks could encourage more regular sharing of reflections and build the research community's capacity to operate effectively in these sometimes challenging contexts. This would build on the very strong goodwill and support for cross-disciplinary learning that exists amongst scholars and practitioners - as evidenced at the Iceland Workshop - and lead to more productive research collaborations to support improved soils governance. 